\title{
TRABALHO DECENTE E A COOPERAÇÃO INTERNACIONAL PARA O DESENVOLVIMENTO HUMANO: ANÁLISE A PARTIR DOS RELATÓRIOS DE DESENVOLVIMENTO HUMANO GLOBAIS
}

\section{DECENT WORK AND THE INTERNATIONAL COOPERATION FOR HUMAN DEVELOPMENT: ANALYSIS FROM GLOBAL HUMAN DEVELOPMENT REPORTS}

\section{SILVIO BELTRAMELLI NETO}

Professor Titular da Pontifícia Universidade Católica de Campinas (PUC-Campinas), Centro de Ciências Humanas e Sociais Aplicadas, Faculdade de Direito, vinculado ao Programa de Pós-Graduação Strictu Senso em Direito, integrante da linha de pesquisa "Cooperação Internacional e Direitos Humanos" e do Grupo de Pesquisa "Direito num Mundo Globalizado. Membro do Ministério Público do Trabalho. E-mail: silviobeltramelli@puc-campinas.edu.br.

MARIA GABRIELA VICENTE HENRIQUE DE MELO Integrante do Programa de Iniciação Científica da Pró-Reitoria da PUC-Campinas e do Grupo de Pesquisa "Direito num Mundo Globalizado", beneficiando-se de fomento na modalidade Bolsa FAPIC/Reitoria da PUC-Campinas. Email: mariaghvicente@gmail.com. 


\section{RESUMO}

Objetivo: O objetivo é responder a seguinte indagação: os Relatórios de Desenvolvimento Humano globais, elaborados no marco do Programa das Nações Unidas para o Desenvolvimento, adotam a concepção de trabalho decente?

Metodologia: Utiliza-se de abordagem dedutiva procedimental bibliográfica lastreada em análise de documentos oficiais, apoiada por bibliografia específica sobre os temas correlatos. Para tanto, elegeu-se para exame os Relatórios de Desenvolvimento Humano Global editados desde a adoção da concepção do Trabalho Decente pela OIT até o ano de 2015, onde foi publicado o RDH temático "O Trabalho como Motor do Desenvolvimento Humano".

Resultados: Concluiu-se haver dado um movimento gradativo de convergência conceitual que, todavia, apenas alcança sua plenitude com o RDH de 2015, ao adotar, de maneira inequívoca, a concepção de Trabalho Decente, o fazendo na qualidade de fator de reforço do Desenvolvimento Humano.

Contribuições: A pesquisa contribui para os estudos a respeito do trabalho como elemento inolvidável do Desenvolvimento Humano, tendo por campo de investigação as manifestações da cooperação internacional.

Palavras-chave: cooperação Internacional; desenvolvimento humano; trabalho decente; relatórios de desenvolvimento humano.

\section{ABSTRACT}

Objective: To answer the following question: do the global Human Development Reports, prepared within the framework of the United Nations Development Program, adopt the concept of decent work?

Methodology: A deductive bibliographical procedural approach based on the analysis of official documents supported by specific bibliography on related topics. The global Human Development Reports published since the adoption of the Decent Work concept by the ILO until 2015 were chosen for examination, where the thematic HDR "Work as the Engine of Human Development" was published.

Results: It was concluded that there was a gradual movement of conceptual convergence that, however, only reached its fullness upon the HDR of 2015 by 
unequivocally adopting the concept of Decent Work as a factor of reinforcement of Human development.

Contributions: The research contributes to studies on work as an unforgettable element of Human Development, having as field of research the as manifestations of international cooperation.

Keywords: International cooperation; human development; decent work; human development reports.

\section{INTRODUÇÃO}

Teoria e prática do desenvolvimento, primeiro como mote de interesse exclusivo da economia e, depois, das ciências políticas e do Direito, foram avançando no círculo das relações internacionais e ganhando atenção qualificada, dentro dos diversos foros de governança global, ao tempo em que seu próprio conteúdo foi sofrendo modificações e aperfeiçoamentos, em resposta às transformações socioambientais.

No âmbito da Organização das Nações Unidas (ONU), o trajeto histórico da cooperação internacional levada a efeito pelo Programa das Nações Unidas para o Desenvolvimento (PNUD) evidencia aquelas mudanças pelas quais passou (e vem passando) a compreensão do desenvolvimento. Já a OIT foi palco de substancial alteração de seu modo de agir, às portas do século XXI, representada pelo advento da concepção de Trabalho Decente. Em ambos os casos, houve influência decisiva de um marco teórico que teve em Amartya Sen seu principal artífice, o qual logrou retomar a associação entre ética e economia, compreensão que havia se perdido nas dinâmicas do capitalismo do século XX.

Resultado direto do emprego das ideias de Sen, o Índice de Desenvolvimento Humano (IDH) passa a ter lugar, nos anos noventa, como marcador alternativo ao Produto Interno Bruto (PIB) e à renda per capita, e, portanto, 
confrontador da ideia que reconhece no crescimento econômico, per si, a causa do desenvolvimento. Confeccionado, desde 1990, por experts independentes, em atendimento a iniciativa do PNUD, os Relatórios de Desenvolvimento Humano (RDHs) globais, sempre contando com duas a três centenas de páginas, contemplam reflexões e demonstrações analíticas e estatísticas acerca da aplicação do IDH em diferentes países e regiões, tornando-se referência mundialmente relevante a respeito do avanço do Desenvolvimento Humano.

Concomitantemente, também inspirado pela teoria seniana, a OIT, em 1999, consagra a concepção de Trabalho Decente como sua nova diretriz nuclear de atuação, sobretudo da cooperação internacional fomentada junto a seus Estados Membros em busca da observância de um marco civilizatório da exploração do trabalho pelo capital.

É sabido que, em 2015, o PNUD fez publicar uma edição do RDH intitulada "O Trabalho como Motor do Desenvolvimento Humano", única dedicada ao tema laboral. Teria sido essa uma abordagem pontual? Inspirado por tal indagação, a pesquisa realizada teve por escopo a verificação do modo como a cooperação internacional para o Desenvolvimento Humano, em especial na perspectiva do IDH, abordou o Trabalho Decente. Para tanto, elegeram-se os RDHs globais editados desde o advento da concepção do Trabalho Decente segundo a OIT para o enfrentamento do seguinte problema de pesquisa: os RDHs globais, elaborados no marco do PNUD, adotam a concepção de Trabalho Decente?

A partir de uma abordagem dedutiva e procedimental bibliográfica lastreada em análise de documentos oficiais apoiada por bibliografia específica sobre os temas correlatos, optou-se, metodologicamente, por uma sistematização condensada compatível com a extensão de um artigo científico das principais ideias, análises e conclusões dos RDHs examinados a respeito das relações de trabalho, buscando-se identificar sua aproximação ou distanciamento com a concepção de Trabalho Decente. 
O propósito principal do resultado desta investigação é contribuir para os estudos a respeito do trabalho como elemento inolvidável do Desenvolvimento Humano, tendo por campo de investigação as manifestações da cooperação internacional.

\section{EVOLUÇÃO CONCEITUAL DO DESENVOLVIMENTO}

O início da disseminação da ideia desenvolvimento é comumente relacionado ao período que sucedeu a Segunda Guerra Mundial ${ }^{1}$, tempo de intensificação de processos de descolonização e de progresso econômico e político de nações cuja situação era reconhecida como de "subdesenvolvimento", o que explica uma compreensão do ímpeto desenvolvimentista atrelado unicamente ao aspecto eminentemente econômico, alusivo à produção de riqueza (HUNT, 2001, p. 34). Com fulcro nesta percepção, as décadas de quarenta e cinquenta testemunharam os chamados países "de Terceiro Mundo" ("subdesenvolvidos") tomando a noção de desenvolvimento como sinônimo de industrialização ao modo dos países "de Primeiro Mundo" (SO, 1990, p. 217 - 231).

Ainda nos anos cinquenta, a superação da noção de desenvolvimento limitada ao à produção de riquezas e ao crescimento econômico, de modo alcançar a pretensão do bem-estar dos indivíduos, teve, na retomada de certas ideias dos economistas clássicos Adam Smith e David Ricardo, seu grande impulso teórico. Plantava-se a semente do que viria a ser designado por Desenvolvimento Social, contemporâneo da difusão das ideias econômicas de John Maynard Keynes e da consolidação política do modelo do Welfare State nos países hegemônicos da época (SANTOS, 2002, p. 137).

\footnotetext{
${ }^{1}$ O desenvolvimento consta do art. 55 da Carta de São Francisco, de 1945, como um dos objetivos a serem promovidos pela ONU.
} 
Os anos setenta vão abrigar mais um estágio de avanço da concepção de desenvolvimento, instado pela persistência da desigualdade social e econômica², aliado à atenção despertada para a preservação e uso adequado dos recursos naturais, principalmente após a Conferência de Estocolmo de 1972, em que a ONU, pela primeira vez, abordou a temática Meio Ambiente e Desenvolvimento em conjunto (AMARO, 2006, p. 59). Conforma-se, neste cenário, o denominado "ecodesenvolvimento", que ascende à pauta da governança global em 1972, durante a Primeira Conferência das Nações Unidas sobre o Meio Ambiente e Desenvolvimento. O caminho estava aberto para a consagração, mais de uma década à frente, do termo "Desenvolvimento Sustentável".

Antes, porém, a Declaração sobre o Direito ao Desenvolvimento da ONU de 1986 confirmou a centralidade do bem-estar da pessoa humana para a concepção jurídica de desenvolvimento. Ademais, a disseminação da expressão "Desenvolvimento Social" vai ser impulsionada pela Cúpula Mundial sobre o Desenvolvimento Social da ONU de 1995 (“Conferência de Copenhague”), que, "diferentemente das demais conferências da agenda social da ONU na década de 90, não teve precedentes. Foi o primeiro grande encontro internacional havido sobre o tema do desenvolvimento social" (ALVES, 1997, p. 142). A Conferência de Copenhague pretendeu estabelecer compromissos estatais de garantia de níveis mínimos de bem-estar social em diferentes aspectos sociais, como educação, saúde, valor do salário mínimo, etc (AMARO, 2003, p. 59; 2006).

Neste entretempo, a noção de Desenvolvimento Sustentável viria a se consolidar com a edição, em 1987, pela ONU do relatório "Nosso Futuro Comum", assinado por Gro Harlem Brundtland, então primeira-ministra norueguesa e chefe da Comissão Mundial sobre o Meio Ambiente e Desenvolvimento instituída pela ONU, em cuja instância adveio aquele estudo que inovara ao vincular a dimensão

2 Para os alertas já trazidos a lume, décadas atrás, por Celso Furtado acerca do mito do desenvolvimento envolto na desigualdade social, cf. FURTADO, 1951 e 2004. 
ambiental do Desenvolvimento Sustentável às ideias de justiça social e solidariedade intergeracional (BRUNTLAND, 1987).

Compromissos para com o Desenvolvimento em sua feição socioambiental traduzidos mais concretamente em objetivos e metas correlatas traçados para um período de quinze anos lograram ser, por pioneiro consenso da comunidade internacional (PNUD, 2003, p. 5), assumidos por força de resoluções da Assembleia Geral da ONU, com a aprovação, no ano de 2000, dos Objetivos do Milênio (ODM), os quais, depois, experimentariam ampliação, aperfeiçoamento e extensão temporal pelo mesmo prazo com a adoção, em 2015, dos Objetivos do Desenvolvimento Sustentável (ODS), também conhecidos como "Agenda 2030".

Já o conceito de Desenvolvimento Humano será consagrado em 1990, no bojo das ações do PNUD, que passa, desde então, a, periodicamente, editar o RDH, como instrumento de veiculação das apurações acerca do IDH, índice conformado por indicadores relativos não apenas a rendimentos, mas também a longevidade e educação, dimensionando aspectos para além dos eminentemente econômicos.

Reconhecidamente, IDH e RDH são resultado direto da aplicação da teoria das capacidades de Amartya Sen. Em síntese, tal teoria, a partir da retomada de inspiração aristotélica da associação entre ética e economia (SEN, 1999, p. 18-19; GARRIDO, 2008, p. 22, 35 e 61), preceitua que o desenvolvimento de um indivíduo é resultado direto da conjugação de suas capacidades, entendida capacidade (capability) como "a liberdade substantiva de realizar combinações alternativas de funcionamentos (ou, menos formalmente, a liberdade para ter estilos de vida diversos)" (SEN, 2010, p. 105). Nesta linha, os "funcionamentos" representam as diversas coisas que uma pessoa pode desejar fazer ou ser (GARRIDO, 2008, p. 40). O conjunto de capacidades pode ser delimitado pelo leque mais restrito ou mais amplo de oportunidades de aquisição de distintos funcionamentos, ou seja, de bens e caminhos que, por livre decisão ("agência") da própria pessoa, representem meios para seu bem-estar segundo suas preferências pessoais (SEN, 1999, p. 56-60). 
Sob este enfoque, a promoção do Desenvolvimento Humano, em poucas palavras, exige ações orientadas à expansão das capacidades a serem exercidas livremente (ALKIRE; DENEULIN, 2006, p. 03) para além da busca da renda, mirando também a longevidade (com saúde e alimentação) e a educação (com qualificação profissional), com eliminação de situações de discriminação e em ambiente politicamente democrático (SEN, 2010, p.120-149). Segundo Sen (2010, p. 124), mais renda não determina mais capacidades, mas sim o exato contrário, sendo certo que há capacidades básicas cuja privação é sinônimo de pobreza (SEN, 2010, p. 120).

Esta mesma proposta teórica animou a construção da concepção de Trabalho Decente e sua adoção pelos Estados Membros da OIT, em 1999, como eixo central de um novo perfil de atuação da Organização para a consecução de seus fins, focado na promoção pela via da cooperação internacional multilateral de quatro objetivos estratégicos, quais sejam, a proteção dos direitos humanos nas relações de trabalho, a geração de empregos de qualidade (dignos), a ampliação da proteção (seguridade) social e o incentivo ao diálogo social (OIT, 1999, p. 6) ${ }^{3}$. A influência da Conferência do Desenvolvimento Social de 1995 sobre a adoção da ideia de Trabalho Decente pela OIT é inequívoca (OIT, 1999, p. 15). O Trabalho Decente viria a ser contemplado, literalmente, em 2015, pelo oitavo objetivo dos ODS ("promover uma parceria mundial para o desenvolvimento: oportunidades de trabalho, acesso aos medicamentos e às novas tecnologias").

Isso, todavia, não significa, necessariamente, que a noção de Trabalho Decente passou a, incontinenti, integrar as análises e propostas desenvolvimentistas do século XXI.

\footnotetext{
${ }^{3}$ Sen, a convite, proferiu a fala inaugural da Conferência Internacional de 1999 da OIT, ocasião da consagração da noção de Trabalho Decente pela instituição, tendo publicado esse discurso na forma de artigo, pelo qual defende a intrínseca vinculação entre Trabalho Decente e proteção de direitos (SEN, 2000).
} 


\section{AS RELAÇÕES LABORAIS NOS RELATÓRIOS DE DESENVOLVIMENTO HUMANO EDITADOS NA PRIMEIRA DÉCADA DA CONCEPÇÃO DE TRABALHO DECENTE}

$\mathrm{O} \mathrm{RDH}$ do ano 2000, intitulado "Direitos Humanos e Desenvolvimento Humano - pela Liberdade e Solidariedade", aborda a inexorável associação entre Direitos Humanos e o Desenvolvimento Humano, a partir do asseguramento de liberdades básicas ("The Seven Freedoms"), a saber: liberdade em face a discriminação (de gênero, raça, etnia, nacionalidade e religião), liberdade em face do medo de afronta à segurança pessoal, da tortura, da prisão arbitrária e de outros atos violentos; liberdade de pensamento, de expressão, de reunião e de deliberação; liberdade para desejar e usufruir de um padrão decente de vida; liberdade para desenvolver e realizar o potencial humano individual; liberdade em face da injustiça e da violação do devido processo legal; e liberdade para o Trabalho Decente ${ }^{4}$, sem exploração (PNUD, 2000, p. 1) . Por outro lado, alertou-se para o fato de que nenhuma das liberdades humanas seria capaz de se autopromover, porquanto dependentes de políticas para seu impulsionamento (PNUD, 2000, p. 6).

Relevante notar que o RDH de 2000 também trata do Trabalho Decente dentro da temática da erradicação da pobreza extrema, explicitando a compreensão segundo a qual a expansão do trabalho em condições indignas deve ser compreendida como consequência da pobreza extrema, premida pelo imperativo de sobrevivência (PNUD, 2000, p. 78). Nesta linha, partindo-se da premissa teórica segundo a qual determinadas liberdades potencializam a expansão de outras, a análise promovida pelo $\mathrm{RDH}$ alça o Trabalho Decente à condição de uma dessas liberdades instrumentais, capazes de contribuir para a ampliação das capacidades ${ }^{4}$ Cumpre notar que a tradução para a língua portuguesa de todos os RDHs converte o termo "Decent
Work" em "Trabalho Digno". Este estudo, contudo, fará uso da tradução "Trabalho Decente",
porquanto afigurar-se mais afeta ao sentido do texto, sob a ótica idiomática brasileira, à falta de uma
definição explicitamente adotada e sistematicamente repetida pelos RDHs para o termo. 
humanas (PNUD, 2000, p. 128). A propósito, foram apresentados dados que expressam certa ampliação das situações de trabalho em condições dignas em várias partes do mundo, conquanto distante do desejável (PNUD, 2000, ps. 52, 241 e 263). O Relatório ainda destacada a importância da ratificação das convenções internacionais da OIT (PNUD, 2000, p. 40), posto que consagram indisputável senso ético de reprovação da exploração desmedida do trabalho.

A tecnologia como instrumento do Desenvolvimento Humano foi o mote para o RDH 2001 ("Fazendo as Novas Tecnologias Trabalharem para o Desenvolvimento Humano"), com a compreensão de que os resultados do avanço tecnológico se afirmam como meio para a ampliação das capacidades humanas, tomadas, à feição de Sen, como "conjunto de coisas que as pessoas podem ser, ou fazer, na vida" (PNUD, 2001, p. 1).

Nesta perspectiva, o documento reforça que, com o surgimento de novas tecnologias, surgem novas profissões e novos modos de trabalho, promovendo uma abordagem muito próxima do prenúncio daquilo que o Fórum Econômico Mundial, capitaneado por seu fundador Klaus Schwab, veio a denominar "Quarta Revolução Industrial" e sua "Indústria 4.0" (SCHWAB, 2016, p. 15-17). Nesta linha, alerta este $\mathrm{RDH}$ para a emergência de um mercado de trabalho mundial voltado aos profissionais das tecnologias de ponta, com uma maior mobilidade de pessoas a pretexto laboral, impulsionada pela escassez de qualificações na Europa, Japão e nos Estados Unidos (PNUD, 2001, p. 29).

Sobre a questão de gênero ${ }^{5}$, enfatiza-se 0 incremento da participação das mulheres em empregos remunerados nos setores de indústrias e serviços, em grande parte dos países - constatação que guarda relação com o fato de as mulheres terem experimentado, na metade final do século $\mathrm{XX}$, maiores taxas de

\footnotetext{
${ }^{5}$ Análises específicas sobre o recorte de gênero são encontradas em absolutamente todos os RDHs, sob o prisma do tema de cada qual. Não obstante, por questão de espaço e foco, essas abordagens, conquanto indispensáveis, à vista do escopo dos relatórios, deixarão de ser mencionadas de modo destacado.
} 
escolaridade e especialização. Todavia, a disparidade de remuneração permanece uma realidade global, conquanto com nuances regionais (PNUD, 2001, p. 16).

O RDH 2002 ("Aprofundar a Democracia num Mundo Fragmentado") asseverou que "a política é tão importante como a economia para um desenvolvimento bem sucedido" (PNUD, 2002, p. v). O fez, porque, a despeito dos avanços mundiais na implantação do regime democrático, o final do século $X X$ denotara um quadro de estagnação ou retrocessos quanto a essa marcha (PNUD, 2002, p. 13 e 34).

Neste contexto, a incapacidade de alguns governos democráticos à época recentemente implantados de gerenciar uma economia capaz de prover empregos em quantidade e qualidade aspiradas pela população é abordada como circunstância que auxilia uma guinada antidemocrática, manifestada em certos atos desses mesmos governos, inclusive mediante campanhas de enfraquecimento dos Poderes Legislativo e Judiciário (PNUD, 2002, p. v e 4). A respeito, a privação de rendimento e mortalidade juvenil são apresentadas por este RDH como um dos problemas mais espinhosos para progresso do Desenvolvimento Humano, a ser combatido com o crescimento econômico, que tem como condição a eficiência das instituições públicas e das regras para "fazer funcionar os mercados" (PNUD, 2002, p. 2).

No plano especialmente nacional, quanto ao tema do trabalho, os sindicatos são reconhecidos como entes privados promotores de importante participação política nas decisões da esfera pública, motivo pelo qual, a uma, a ratificação da Convenção n. 87 sobre Liberdade Sindical e Negociação Coletiva da OIT é desejável (sendo registrado como indicador de boa governança); e, a duas, a restrição da atuação de entidades sindicais deve ser tomada por restrição da democracia (PNUD, 2002, p. 36, 55 e 83). Já na esfera internacional, o RDH de 2002 insta o enfrentamento do que avalia ser um déficit democrático das organizações internacionais em geral, em especial aquelas relacionadas ao 
mercado, como OMC e Banco Mundial, entre outras, sendo, contudo, de se destacar que a OIT não é sequer citada neste momento de análise (PNUD, 2002, p. 112-121).

O RDH de 2003 ("Um Pacto entre Nações para Eliminar a Pobreza Humana") é inteiramente dedicado aos Objetivos do Milênio (ODM), buscando identificar os principais entraves para seu cumprimento (com exames gerais e individuais por objetivo dos ODM), em um momento histórico em que se podia constatar, em termos gerais, um retrocesso no Desenvolvimento Humano (PNUD, 2003 , p. v). Sob esta ótica, o documento reporta, com preocupação, as taxas de desemprego dos países membros da Organização para a Cooperação e Desenvolvimento Econômico (OCDE) (PNUD, 2003, p. 299).

Por outro lado, tal RDH, amparado em contribuição do economista Joseph Stiglitz, faz questão de pontuar que a ligação do Desenvolvimento Humano com o crescimento econômico não elimina, ao contrário, suscita a análise crítica do tipo de crescimento que a globalização vem promovendo, posto que sempre há que se procurar pelo crescimento econômico que gere o bem-estar das pessoas (PNUD, 2003, p. 80).

A única menção expressa ao termo "Trabalho Decente" acontecerá no espaço de indicadores alusivos ao Objetivo n. -8 dos ODM, mais especificamente de sua meta de desenvolvimento e execução de estratégias para o Trabalho Decente de jovens. No particular, o documento apenas registra a evolução do desemprego juvenil entre 1990 e 2001, com números gerais e desagregados por país e por gênero (PNUD, 2003, p. 232-236), monitoramento que se repetirá nos relatórios subsequentes.

Em 2004, o RDH "Liberdade Cultural num Mundo Diversificado" dirige-se a grupos minoritários e socialmente excluídos, exaltando a diversidade cultural como circunstância que favorece e é favorecida pelo Desenvolvimento Humano ${ }^{6}$. Sob esta

${ }^{6}$ É possível pensar que a "agência" é o elemento da Teoria de Sen que melhor permite trazer o tema da diversidade para perto da concepção de Desenvolvimento Humano, conforme sugere a introdução 
ótica temática, o Relatório toca as relações de trabalho no seio dos alertas explícitos contra a discriminação denotada nas elevadas taxas de desemprego de grupos de trabalhadores migrantes, verificadas em todas as partes do mundo, sendo que, não raras vezes, este quadro é sufragado por políticas xenófobas de Estado, travestidas do discurso de proteção e privilégio dos nacionais em matéria de acesso às oportunidades de trabalho, ou, quando muito, há acolhimento efêmero e legalmente precário de migrantes, dirigido à exploração temporária da força de trabalho (PNUD, 2004, p. 100-103). Tal como seus antecessores, conquanto o RDH de 2004 não tome a concepção de Trabalho Decente como referência de detida análise, as reflexões sobre discriminação de migrantes em matéria laboral aproximam o relato de ao menos uma das dimensões da concepção de Trabalho Decente que não unicamente a geração de empregos: a proteção de direitos humanos no trabalho.

"Cooperação Internacional numa Encruzilhada: Ajuda, Comércio e Segurança num Mundo Desigual" é o título do RDH de 2005, o qual, apesar de reconhecer que o processo histórico do desenvolvimento foi, desde sempre, pautado pela busca de caminhos e políticas para o desenvolvimento de nações pelos seus próprios atores estatais e privados, se propõe a trazer a lume a responsabilidade de Estados e demais atores internacionais na consecução do objetivo desenvolvimentista de outros Estados, sob o prisma da cooperação internacional (PNUD, 2005, p. v). As análises apresentadas neste Relatório são formuladas tendo por referência os ODM e lançam luzes sobre os obstáculos causados pela deficiência ou emprego inadequado da ajuda financeira internacional, pelo descomprometimento do comércio internacional com o Desenvolvimento Humano e pelas consequências sociais devastadoras dos conflitos armados.

Exorta-se que a ajuda financeira de nações prósperas a benefício de nações pobres não seja encarada como caridade ou custo, mas como um imperativo moral possibilidade das pessoas viverem o tipo de vida que escolheram - e com a provisão dos instrumentos e das oportunidades para fazerem as suas escolhas" (PNUD, 2004, p. v). 
de investimento, que deve ser adequadamente disponibilizado, sob eficiente governança (PNUD, 2005, p. 75-80). Ao tratar da questão da ajuda, o RDH 2005 especifica a necessidade de seu direcionamento para a ampliação da proteção social em países pobres, em especial pela via de programas sociais de transferência de renda, que salvem famílias da prisão atávica ao ciclo da pobreza, permitindo a escolarização e a inserção no mercado de trabalho (PNUD, 2005, p. 82). Ainda que não explicitamente, a preocupação com a expansão da proteção social faz $\mathrm{oRDH}$ agir em favor da promoção de um dos quatro objetivos estratégicos do Trabalho Decente.

No que pertine ao comércio internacional, o RDH de 2005, a partir de estudos comparativos - v.g. entre Peru e Brasil de um lado, e China, Índia e outros países da Ásia Oriental, de outro (PNUD, 2005, p. 120) - problematiza, fortemente, o cânone neoliberal predominante na direção da eliminação das barreiras nacionais ao mercado internacional pelos países pobres ou em desenvolvimento como inexorável geradora de crescimento econômico e, por conseguinte, bem-estar (PNUD, 2005, p. 120-121). Sustenta o RDH haver que se frear a força do poder econômico sobre as negociações atinentes ao comércio internacional praticado diretamente entre países, assim como dentro dos foros internacionais, na medida em que tal cenário leva a uma condição global de proliferação de empregos baratos e indignos, além de fragilização de direitos ${ }^{7}$.

\footnotetext{
${ }^{7}$ México, Guatemala, Estados Unidos e a América Latina têm seus casos citados como paradigmas da deletéria influência do poder econômico e do comércio internacional enquanto geradores de riqueza concentrada e exacerbação da vulnerabilidade denotada por empregos precários, rebaixamento de salários e desmantelamento dos direitos trabalhistas (PNUD, 2005, p. 122-124). Dizse: "O que é necessário é uma combinação do reforço dos direitos do trabalho com as instituições e políticas que possa facilitar o ajustamento e a adaptação à mudança. [...] Para maximizar os ganhos de bem-estar resultantes do comércio e reforçar o interesse político da participação no comércio, é importante que os vencedores compensem os perdedores. Esta compensação pode assumir várias formas, incluindo transferências entre países e políticas públicas nacionais para a criar as condições de protecção e provisão de oportunidades aos perdedores" (PNUD, 2005, p. 124-125).
} 
De outro lado, a contenda entre Israel e Palestina é trazida como exemplo das consequências danosas do conflito para o crescimento econômico e para a inserção no mercado de trabalho dos palestinos (PNUD, 2005, p. 158).

O RDH de 2005, diga-se, é um dos primeiros relatórios que se posiciona de modo mais direto e enfático contra a geração de empregos em más condições e o menoscabo de direitos trabalhistas, além de repisar a exortação à ampliação da proteção social, encampando, deste modo, três dos quatro objetivos estratégicos do Trabalho Decente, ainda que não tenha se valido dessa associação de forma expressa.

O RDH de 2006 ("Além da Escassez: Poder, Pobreza e a Crise Mundial da Água") destacou, de modo bastante específico e sempre com aderência aos ODM, a questão da escassez da água e sua relação com o Desenvolvimento Humano, não abrindo flancos para reflexões mais detidas sobre o trabalho, a não ser menção pontual sobre como, em comunidades com privação de acesso à água potável, a busca por fontes desse bem essencial à vida humana e os cuidados com a saúde pela sua indisponibilidade acaba por subtrair tempo que poderia ser dedicado ao trabalho produtivo (PNUD, 2006, p. 36 e 46).

Os anos de 2007 e 2008 foram abarcados por um único RDH, intitulado "Combater a Mudança do Clima: Solidariedade Humana em um Mundo Dividido", cujo enfoque novamente recai sobre tema eminentemente ambiental e suas consequências para o Desenvolvimento Humano. A atividade laboral é frequentemente abordada neste relatório na perspectiva da influência do meio ambiente na empregabilidade. O RDH 2007/2008 parte da premissa segundo a qual a ampliação das capacidades está relacionada também à expansão da produtividade, com o que contribuem, decisivamente, nutrição, saúde e educação, todos suscetíveis ao meio ambiente (PNUD, 2008, p. 74). A propósito, este Relatório aponta a nutrição, a educação (prejudicada pela busca de rendimentos com o 
trabalho infantil) e a saúde como componentes do rol de bens e oportunidades humanas erodidas em situações de choque climático (PNUD, 2008, p. 86-88).

Releva pontuar, sob a ótica do Trabalho Decente (mais uma vez não explicitamente abordado no documento), que o RDH 2007/2008, repetindo seus antecessores mais imediatos, também dedica reflexão específica sobre a amplificação da proteção social em tempos de choque climático, apontando como um dos caminhos a implementação de programa de empregos que favoreça a obtenção de renda no labor agrícola (mitigando os efeitos da questão ambiental no desemprego rural) e, por conseguinte, minore o impacto do evento climático na produção de alimentos. (PNUD, 2008, p. 181-184).

Em 2009, a preocupação retorna à situação migratória, enfocada no $\mathrm{RDH}$ "Ultrapassar Barreiras: Mobilidade e Desenvolvimento Humano". A questão do trabalho perpassa praticamente todas a análises contidas no documento, com ênfase para as dificuldades de inserção do migrante no mercado estrangeiro e suas razões ligadas, no mais das vezes, à discriminação associada à pressão do desemprego estrutural. Desmistificando compreensões disseminadas em contrário, o RDH 2009 compila uma série de estatísticas e estudos que mostram que a migração, em sua maior parte, ocorre respeitando fluxos entre nações de mesmo nível de desenvolvimento, bem como negam evidências de rebaixamento salarial provocado por inserção de migrantes em certo mercado de trabalho, até porque, ainda segundo o documento, não há evidências seguras sobre um padrão de impactos da migração no mercado de trabalho (PNUD, 2009, p. v e 85). Sabe-se, contudo, que praticamente toda migração ocorre, em larga medida, com o apelo por uma melhor oportunidade de trabalho (PNUD, 2009, p. 26 e 29).

Com vistas à alteração deste quadro deletério do Desenvolvimento Humano de migrantes e nativos, o RDH de 2009 propõe uma série de providências estatais em ordem à pretendida alteração deste quadro histórico, mas não deixa de imputar responsabilidades a atores não estatais. Para ambos (Estado e atores privados), a 
afirmação dos direitos humanos, inclusive os trabalhistas (PNUD, 2009, p. 5), para os migrantes é um imperativo ${ }^{8}$.

Controle extremamente restritivo de ingresso de migrantes ao país e de sua contratação formal são criticados e tomados como obstaculização de seu acesso a mercado formal de trabalho (PNUD, 2009, p. 66), embora a tolerância de países desenvolvidos com a exploração intermitente de trabalho de migrante em situação irregular de estada ou de emprego seja denunciada (PNUD, 2009, p. 2-3). Políticas públicas de seguridade social voltadas aos migrantes, em especial pelo período que não ascendem ao mercado de trabalho e em tempos de recessão econômica, são demandadas (PNUD, 2009, p. 54 e 106). Já no espectro privado, o RDH conclama o respeito aos direitos humanos trabalhistas pelos empregadores, assim como exorta ONGs e Sindicatos a desempenharem, com afinco, seu papel assistencial e reivindicatório em face aos interesses dos migrantes (PNUD, 2009, p. 101).

\section{UM PASSO ADIANTE: TRABALHO DECENTE COMO FATOR DE REFORÇO DO DESENVOLVIMENTO HUMANO}

O título do RDH 2010 - "A Verdadeira Riqueza das Nações: Vias para o Desenvolvimento Humano" retoma uma máxima de Adam Smith (à qual se apega Amartya Sen em suas reflexões) aludida no primeiro RDH de 1990, dando, assim, o tom revisionista deste relatório, por ocasião de sua vigésima edição.

Remontando os dados e exames empreendidos ao longo de duas décadas, o RDH de 2010 indica já haver sido possível demonstrar, com dados de série

\footnotetext{
${ }^{8}$ Conquanto sem admitir, o RDH 2009 se vale o padrão da Declaração da OIT sobre Princípios e Direitos Fundamentais no Trabalho de 1998 para arrolar direitos humanos de migrantes cuja observância independe de ratificação dos Estados de tratados internacionais que contemplem tais direitos, tratando, pois, aquela Declaração como norma imperativa de Direito Internacional (jus cogens). Vale recordar que a Declaração da OIT de 1998 é a referência para a compreensão do conteúdo do objetivo estratégico da promoção do Trabalho Decente relativo à salvaguarda de direitos humanos nas relações laborais.
} 
histórica, que os três componentes originais do IDH (rendimento, longevidade e educação) (PNUD, 2010, p. vi) não ostentam relação de causalidade, pois experiências monitoradas mostram haver países pobres ou em desenvolvimento que experimentaram melhoria em seus níveis de saúde e educação, a despeito de não crescerem economicamente, havendo, por outro lado, nações com substanciais ganhos econômicos, sem o correspondente incremento do acesso à saúde e educação de sua população. Estaria corroborada, pois, a tese de que o rendimento não é condição para a expansão dos outros elementos. Claras também são as evidências colhidas de que a democracia é ambiente exigido para o aperfeiçoamento estável de melhores condições de acesso à saúde e educação (PNUD, 2010, p. 48-56).

Ainda no campo crítico da economia ortodoxa, o RDH de 2010 desmente uma pretensa relação necessária de causalidade entre crescimento econômico e oportunidades de Trabalho Decente, embora admita que essa relação possa se verificar em alguns casos (PNUD, 2010, p. 51) ${ }^{9}$.

Diante deste quadro, este RDH enfatiza o papel estatal destacado na mediação da relação entre empresas, trabalhadores, comunidades e o próprio Estado, em especial pela via da regulação e de sua salvaguarda pelas instituições, com vistas à limitação do abuso do mercado e à redistribuição de renda, com isso estabelecendo um verdadeiro contrato social entre sociedade, mercados e Estado. Sob esta ótica, o mercado é necessário ao Desenvolvimento Humano, mas não elemento exclusivo para seu fomento, demandando freios, dado que a experiência mostra que a plena liberdade do mercado enseja barateamento da mão-de-obra associada à explosão do exército de reserva (desemprego estrutural) e ao desprezo pela saúde dos trabalhadores (PNUD, 2010, p. 65-66). Contudo, o setor privado

\footnotetext{
${ }^{9} \mathrm{O}$ mesmo, afirma o documento, pode-se dizer quanto ao meio ambiente e à distribuição equitativa de ganhos, posto que é possível verificar situações em que o crescimento econômico acarreta degradação ambiental e aprofundamento da desigualdade social, com intensificação da acumulação de rendimentos (PNUD, 2010, p. 52).
} 
(subjetivamente mais amplo que o mercado), não deixa de ser fulcral para o Desenvolvimento Humano, posto que o mercado pode propiciar, em conjunto com o Estado, acesso a bens e serviços importantes para o aumento das capacidades - a exemplo de serviços de telefonia, de crédito e de seguros sociais (PNUD, 2010, p. 65) - , cabendo à sociedade civil organizada (ONGs, imprensa e sindicatos) resistir aos arroubos exploratórios do capital (PNUD, 2010, p. 67).

Estes dizeres consagram uma compreensão que diverge da onda econômica ultraliberal, travestida do discurso da austeridade fiscal, disseminada nas primeiras décadas do século XXI como motor do desenvolvimento. Quanto ao ponto, o RDH de 2010 faz constar que "quando o Estado não é inclusivo, é difícil para as instituições responsáveis moderar os efeitos destrutivos dos mercados descontrolados sobre outras dimensões do bem-estar" (PNUD, 2010, p. 66). Bem por isso, este RDH desconsidera e contrapõe o corrente discurso sobre o custo com os direitos trabalhistas como desvantagem comercial e obstáculo ao desenvolvimento econômico, ao passo em que exorta a proteção do emprego (PNUD, 2010, p. 78 e 85).

Ao tempo em que revisita critérios e metodologias de análises e percepções de seus antecessores, o RDH de 2010 também traz como novidade a instituição de três índices específicos, o IDH Ajustado à Desigualdade, o Índice de Desigualdade de Gênero e o Índice de Pobreza, além da adoção de indicadores relativos à vulnerabilidade (PNUD, 2010, p. 5). Justamente dentre tais indicadores de vulnerabilidade passa a figurar um indicador intitulado "Trabalho Decente", composto (com desagregação por gênero) por: taxa de população empregada, taxa de empregos formais, taxa de emprego vulnerável (trabalho familiar não pago ou por conta própria), taxa de pessoas empregadas que vivem com menos de US $\$ 1,25$ por dia, taxa de desemprego por nível de educação, taxa de trabalho infantil e número de dias úteis de gozo de licença maternidade remunerada e obrigatória (PNUD, 2010, p. 197-200). Conquanto bem-vindo, é de se perceber que a composição desse 
novo indicador (que não viria a ser reeditado nos RDHs subsequentes) está muito aquém de abarcar apurações atinentes a todos os quatro objetivos estratégicos da promoção do Trabalho Decente, tal como concebidos pela OIT.

A propósito da justificação da adoção do Trabalho Decente como indicador de vulnerabilidade, relevante, neste $\mathrm{RDH}$, é o reconhecimento explícito da importância do trabalho para o Desenvolvimento Humano, não apenas pelo seu aspecto de renda, mas pelo que representa em termos de subjetividade humana, deixando claro que não se está a tratar de um elemento de vulnerabilidade apenas econômica ${ }^{10}$.

Ademais, o RDH de 2010 destaca a dramaticidade do "pico" de desemprego mundial alavancado pela crise econômica global de 2008 (PNUD, 2010, p. 83), bem como notabiliza o trabalho não remunerado ( $v . g$. o familiar, voluntário ou por conta própria) como fator que deve ser levado em consideração para uma análise mais fidedigna do crescimento econômico (PNUD, 2010, p. 118).

$\mathrm{Na}$ esteira da Conferência das Nações Unidas sobre Desenvolvimento Sustentável ("Rio+20"), o RDH de 2011 - "Sustentabilidade e Equidade: um Futuro Melhor para Todos" não conferiu a mesma atenção dada pelo seu antecessor às relações de trabalho, nas análises que empreendeu. As luzes são todas lançadas à ideia de sustentabilidade (sob o ponto de vista ambiental), associando-a, diretamente, à questão da equidade em uma relação de mútua influência ou retroalimentação. Nesta toada, o trabalho aparece, amiúde, abordado nos contextos de análise que consideram a geração de empregos circunstância necessária ao enfrentamento da privação de renda e os examinam sob a perspectiva da interação com o meio ambiente (PNUD, 2011, p. 5). Demais disso, o provimento de ampla

\footnotetext{
10 "A situação de emprego afecta também o sentido subjectivo de bem-estar das pessoas. Qualquer análise da vulnerabilidade deve assim considerar prudentemente a insegurança no emprego e as fontes de instabilidade económica, especialmente importantes agora que a economia mundial se debate para emergir da recessão mais profunda em várias décadas e da perda de milhões de empregos" (PNUD, 2010, p. 83).
} 
proteção social, desta feita tomando em conta os riscos ambientais associados aos econômicos, é reiterado (PNUD, 2011, p. 83 e 99).

Novo RDH viria a ser editado apenas em 2013, sob o título "A Ascensão do Sul: Progresso Humano num Mundo Diversificado", destacando as experiências exitosas de incremento do Desenvolvimento Humano por países do Sul Global que experimentaram crescimento econômico substancial nas primeiras décadas deste século XXI. São nações que romperam barreiras e quebraram paradigmas do desenvolvimento, evoluindo seu papel para além de fornecedores de matéria-prima, passando a economias dinâmicas e com crescente influência política.

Corrobora-se a negação do crescimento econômico como causa exclusiva do Desenvolvimento Humano, retomando seis tipos de "crescimento indesejado", já anteriormente reportados pelo $\mathrm{RDH}$ de 1996: crescimento sem emprego; crescimento sem escrúpulos (com aumento das desigualdades); crescimento sem voz (negada participação política às comunidades vulneráveis); crescimento sem raízes (que copia modelos inadequados de outras experiências); e crescimento sem futuro (com exploração desenfreada dos recursos naturais) (PNUD, 2013, p. 65).

Considerando o Trabalho Decente como resultado da ampliação das principais capacidades, nomeadamente alimentação, educação, saúde e qualificações (PNUD, 2013, p. iv), o RDH de 2013 alerta para o fato de que o rápido crescimento dos países do Sul Global exige oferta compatível de Trabalho Decente, sobre pena de conflagração civil (PNUD, 2013, p. 15 e 94). A resposta a este cenário demográfico demandará níveis de escolaridade mais elevados e aumento de oportunidades de emprego produtivo, reduzindo-se o desemprego, notadamente das mulheres e trabalhadores mais velhos (PNUD, 2013, p. 7). Para além disso, citou-se estudo da OIT, segundo o qual alterações na composição das receitas e despesas dos Estados, com o propósito específico e politicamente neutro de promoção do emprego e do Desenvolvimento Humano, seria capaz de gerar cerca de dois milhões 
de empregos em trinta e três das economias desenvolvidas, no período de um ou dois anos (PNUD, 2013, p. 21) ${ }^{11}$.

Ademais, o RDH de 2013 retoma posicionamento contra a flexibilidade laboral, por justificar práticas que comprometem as condições de Trabalho Decente. Deste modo, conquistas como a legislação laboral sobre salário mínimo, proteção do emprego, limites da jornada de trabalho, segurança social e modelos contratuais seguros, tomadas em conjunto, afiguram-se medidas de redução da desigualdade, da insegurança e dos conflitos sociais, não merecendo crédito a visão da regulamentação laboral como dado prejudicial à geração de empregos (PNUD, 2013, p. 53).

Este mesmo RDH atenta para a sociologia do trabalho do século $X X I$, abordando os avanços das tecnologias da informação como facilitadores do comércio de serviços que exigem diferentes níveis de qualificações - desde o trabalho menos qualificado, como em call centers e inserção de dados, passando pelo pela qualificação média, exigida nos serviços administrativos e de contabilidade, alcançando a alta qualificação profissional demandada pelos setores da arquitetura, animação digital, exames médicos e programação de software, entre outros (PNUD, 2013 , p. 45). Por outro lado, o crescimento do comércio de serviços, conquanto atraia novos trabalhadores (sobretudo mulheres), alargando as suas escolhas, também pode ensejar más condições de trabalho, em razão da busca pelos custos baixos auferidos, por exemplo, junto a salários e ambiente de trabalho. Do mesmo modo, alguns governos são levados a resistir ao necessário reforço dos direitos dos trabalhadores, ao pretexto de evitarem o aumento de custos de produção e a redução da competitividade (PNUD, 2013, p. 50).

\footnotetext{
11 Nesta linha, Brasil e Índia são mencionados como paradigmas, em razão da adoção de políticas públicas de transferência de renda em conjunto com "programas de direito ao trabalho", opções até então consideradas equivocadas ou ineficazes pelos mais tradicionais modelos de desenvolvimento (PNUD, 2013, p. 23). Não obstante, adverte-se que as transferências de renda não devem ser encaradas como meras substitutas dos rendimentos auferidos do Trabalho Decente (PNUD, 2013, p. 86).
} 
O RDH subsequente de 2014 - "Sustentando o Progresso Humano: Redução da Vulnerabilidade e Construção da Resiliência" preocupou-se com o Desenvolvimento Humano de pessoas que integram "grupos estruturalmente vulneráveis" - assim compreendidos em razão de diferentes fatores como género, etnia, deficiência física ou localização geográfica, entre outros - considerando distintas realidades verificadas entre países e mesmo dentro dos próprios países (PNUD, 2014, p. 6). Este documento é pródigo na aplicação aos grupos vulneráveis das percepções e predições sobre o mundo do trabalho já registradas anteriormente, tais como a centralidade do trabalho para o fortalecimento da agência e das capacidades humanas e a importância do emprego para a segurança pessoal e coesão social, transformando a política pública pelo pleno emprego um imperativo para a promoção do Desenvolvimento Humano (PNUD, 2014, p. 6 e 70). Assim também porque o trabalho, para além do salário, é, ao mesmo tempo, componente essencial da subjetividade humana (PNUD, 2014, p. 13).

Reafirma-se, ademais, a compreensão de que crescimento econômico que não gera empregos decentes falha na promoção do Desenvolvimento Humano, como se pode inferir de experiências de países em desenvolvimento com altos índices de empregos precários, sendo a informalidade realidade que assola mais de $40 \%$ dos trabalhadores ativos em $2 / 3$ dos 46 países emergentes e em desenvolvimento (PNUD, 2014, p. 7). O relatório encampa dados que mostram que quase metade da população ativa mundial está submetida a emprego vulnerável, em condições de precariedade e baixa remuneração, sendo que o elevado número de trabalhadores pobres indica proliferação de rendimento laboral abaixo do necessário para uma vida digna (PNUD, 2014, p. 44). Destaca-se, em adição, a proliferação dos empregos atípicos, entendidos como "um trabalho involuntariamente a tempo parcial ou um trabalho temporário, nos países avançados, e um emprego informal nos países em desenvolvimento" (PNUD, p. 70). 
Assevera-se que a reversão do déficit de postos de Trabalho Decente exige políticas públicas atentas aos grupos vulneráveis e voltadas ao pleno emprego digno, i.e. com pagamento de salários razoáveis, contratação formal, prevenção de despedimento abrupto, defesa intransigente de direitos trabalhistas, observando-se um sistema de proteção social amplo, que alcance os trabalhadores informais e que seja sensível à condição especial de indivíduos assolados por vulnerabilidade não apenas econômica, decorrente da condição gênero, raça, etnicidade e deficiência física (PNUD, 2014, p. 3, 95-96 e 121). Contudo, o RDH de 2014 admite que os paradigmas desta quadra histórica relativos à globalização de standards neoliberais alusivos à "autocorreção" do mercado de trabalho pelos mercados, às políticas de austeridade (com redução da proteção social), aos mercados de trabalho flexíveis e à preponderância de políticas macroeconômicas fulcradas em estabilização de preços (ao invés da promoção do pleno emprego), agravadas pela crise financeira mundial, consubstanciam um amalgama de forças contrárias à disseminação dos empregos dignos nos âmbitos nacionais (PNUD, 2014, p. 20).

A propósito da crise econômica mundial de 2008, este RDH é enfático ao afirmar que seu causador, o sistema financeiro internacional desregulamentado, "não está adaptado para minimizar as vulnerabilidades e proteger os ganhos de desenvolvimento humano", tendo acarretado a perda de muitos milhões de postos de trabalho, além do decréscimo do PIB, com especial dano para jovens, trabalhadores pouco qualificados e trabalhadores urbanos (PNUD, 2014, p. 125). $\mathrm{Na}$ mesma toda, excerto do Relatório de autoria de Juan Somavia - ex-Diretor Geral da OIT e, no seu âmbito, artífice da concepção de Trabalho Decente - clama por investimentos na economia real, diante da capacidade destrutiva de empregos dignos demonstrada pela economia financeira virtual.

Fechando a abordagem de todas as dimensões dos quatro objetivos estratégicos do Trabalho Decente, o RDH de 2014, defendendo o aprofundamento dos compromissos éticos e jurídicos internacionais em prol dos empregos dignos e 
da proteção social e dirigindo-se aos foros de governança global, cita a estrutura tripartite da OIT como paradigma de cooperação proveitosa entre os atores estatais e não estatais em nível global (PNUD, 2014, p. 33), ainda mais bem-vinda em tempos de exacerbação das más condições de trabalho ensejadas pelas cadeias globais de valor (PNUD, 2014, p. 115).

No que pertinte aos dados, este Relatório vale-se de muitos indicadores sobre mercado de trabalho, que, juntamente com outros, compõem os monitoramentos do "Índice de Desigualdade de Género (IDG)" (PNUD, 2014, p. 178), das "Competências sociais" (PNUD, 2014, p. 206), da "Insegurança pessoal" (PNUD, 2014, p. 210) e das "Perceções de bem-estar" (PNUD, 2014, p. 226).

O grau de importância que as relações de trabalho assumem nas análises dos RDHs de 2013 e 2014 prenunciaram o que estava por vir: um relatório que reconhece "O Trabalho como Motor do Desenvolvimento Humano". Com este título, o RDH de 2015 escancara a fundamentalidade do trabalho para a promoção do Desenvolvimento Humano, para tanto mantendo-se fiel ao marco teórico seniano ${ }^{12}$. Sem deixar de repisar diversas percepções sobre o labor e sua importância para o Desenvolvimento Humano, o RDH de 2015 aborda-o de uma maneira distinta do visto até então, no que pertine ao Trabalho Decente, posto que organiza suas reflexões e análises em modo totalmente alinhado com a concepção da OIT, bem como com os à época recém aprovados ODS e seu oitavo objetivo (PNUD, 2015, p. 1). De saída, distinguem-se as categorias "trabalho" e "emprego", tomando-se o primeiro como conceito mais abrangente em comparação ao último, por abarcar o trabalho voluntário e o trabalho criativo, dimensões a serem consideradas dentro de qualquer análise no campo laboral (PNUD, 2015, p. 1 e 4).

\footnotetext{
12 "O trabalho como motor do desenvolvimento humano pressupõe mais do que apenas a existência de empregos, prende-se também com o alargamento das escolhas dos indivíduos e com a garantia da existência de oportunidades, o que implica assegurar que estejam disponíveis e acessíveis oportunidades de trabalho remunerado adequadas e de qualidade para aqueles que querem e necessitam trabalho remunerado" (PNUD, 2015, p. 20). Para Sen (1997, p. 155), o trabalho é a única via que possibilita o crescimento econômico em conjunto a melhorias sociais de forma concomitante.
} 
Não implicação do Trabalho Decente pelo crescimento econômico, a distinção entre emprego e emprego digno, a prevalência de políticas públicas em favor do pleno emprego de qualidade e a necessidade de proteção social ampla são afirmações recorrentes nos RDHs anteriores e repetidas no documento em exame.

O RDH de 2015 traz um esclarecimento conceitual definitivo sobre o papel do trabalho para o Desenvolvimento Humano, ao atribuir à atividade laboral em condições dignas a qualidade de fator de reforço das capacidades individuais e, por conseguinte, do próprio Desenvolvimento Humano (PNUD, 2015, p. iii e 1), em uma relação classificada como "sinérgica"13. A contrario sensu, o labor indigno (ou indecente) - como devem ser classificados os trabalhos infantil, escravo, em atividades ilícitas e precário, de ocorrência estatisticamente reportada no Relatório (PNUD, 2015, p. 48 e 88) - afronta o Desenvolvimento Humano, permitindo concluir que a atividade laboral, em si, não é, necessariamente, motor do Desenvolvimento Humano, posto depender "da qualidade do trabalho, das condições do trabalho, do valor social do trabalho, etc" (PNUD, 2015, p. 6-7 e 46-52) ${ }^{14}$.

No que tange à medição estatística dos trabalhos de qualidade, o RDH de 2015, sem ser conclusivo, traz algumas propostas e problematiza alguns aspectos (PNUD, 2015, p. 39 e 63-71), dentro deste tema de indicadores de monitoramento, bastante espinhoso mesmo no âmbito da OIT (ANKER, 2003; ILO, 2008). A respeito,

13 "A relação entre o trabalho e o desenvolvimento humano é sinérgica. O trabalho reforça o desenvolvimento humano, garantindo rendimentos e meios de subsistência, reduzindo a pobreza e assegurando um crescimento equitativo. O desenvolvimento humano - tendo em conta o seu contributo para a saúde, o conhecimento, as competências e a consciencialização - aumenta o capital humano e alarga o leque de oportunidades e escolhas" (PNUD, 2015, p. 4).

14 A propósito do valor social do trabalho, diz o $\mathrm{RDH}$ : "O trabalho reforça a relação trabalhodesenvolvimento quando não se limita a proporcionar benefícios individuais e contribui para a consecução de objetivos sociais comuns. O trabalho que aumenta o rendimento e reduz a pobreza não só diminui as desigualdades como pode mitigar tensões sociais, ao mesmo tempo que o rendimento do trabalho pode ser tributado a fim de gerar recursos para o desenvolvimento humano. $O$ trabalho de prestação de cuidados a idosos ou a pessoas com deficiência ajuda a que mantenham as suas capacidades e reforça a coesão social, enquanto a assistência à infância reforça as capacidades das gerações futuras. Os trabalhadores podem também estabelecer laços econômicos e sociais e reforçar a confiança nos outros e nas instituições, o que também consolida a coesão social" (PNUD, 2015, p. 42). 
também demanda a revisão dos indicadores que vinham sendo utilizados pelos próprios RDHs, ante o advento dos ODS e de seus novos objetivos e metas (PNUD, 2015, p. 28-29).

A propósito, denotando alinhamento com os ODS, o RDH de 2015 destaca o conceito de "trabalho sustentável", definido como aquele que "promove o desenvolvimento humano, reduzindo e eliminando simultaneamente certas externalidades negativas que podem verificar-se em diferentes escalas geográficas e temporais" (PNUD, 2015, p. 42), assumindo-se que o Desenvolvimento Sustentável depende do Trabalho Sustentável, ao mesmo tempo em que aquele tem implicações consideráveis para esse, levando até mesmo em mudanças no processo produtivo (PNUD, 2015, p. 16-19, 150-152 e 155-159).

Todavia, os desafios identificados são muitos. Dois deles mereceram destaque pelo RDH de 2015: as cadeias globais de valor (CGV) e o avanço tecnológico. Quanto às primeiras, ressalta-se que a integração proporcionada por esse fenômeno da globalização e a consequente "deslocalização do trabalho" tem benefícios, como a geração de empregos para países em desenvolvimento, mas também tem se mostrado campo para a ampliação da precariedade das condições laborais e rebaixamento das proteções sociais, em vista de sua flexibilidade aliada à voraz competitividade, aprofundando, por conseguinte, as desigualdades sociais (PNUD, 2015, p. 8-11). Já revolução tecnológica vivenciada tem alterado não apenas a morfologia das relações de trabalho, mas também as exigências e oportunidade de ingresso e manutenção no mercado laboral, favorecendo um menor contingente de pessoas com elevado nível de qualificação em certas áreas e prejudicando sobremaneira um grande contingente de pessoas não qualificadas ou qualificadas em áreas tomadas pela tecnologia (PNUD, 2015, p. 14-15). Situações emergentes específicas, como economia colaborativa, crowdworking, trabalho flexível e trabalho criativo (virtual voluntário e start-ups) são brevemente examinadas 
com comedido otimismo e assentes preocupações, em especial na perspectiva da intensificação de vulnerabilidades e precarizações (PNUD, 2015, p. 99-109).

O Relatório avança ao falar em "bem-estar dos trabalhadores", baseado em direitos, benefícios, proteção social e combate às desigualdades, o que passa, entre outras tantas medidas, pela proteção da liberdade e da ação sindical e pela imperiosidade da ampliação do número de Estados comprometidos com as normas internacionais fundamentais de proteção do trabalho, notadamente as preceituadas pela OIT (PNUD, 2015, p. 21-27). Visando a promoção do bem-estar do trabalhador, propõe-se um assim denominado "novo contrato social mundial tripartite", alicerçado na consecução, sobretudo nos âmbitos nacionais, de uma Agenda de Trabalho Decente conformada por quatro pilares: criar emprego e desenvolver as empresas, normas e direitos no trabalho, proteção social e governação e diálogo social (PNUD, 2015, p. 26-27). Bem por isso se pode afirmar que, de uma forma explícita, o RDH de 2015 é o primeiro dentre todos os RDHs até então editados que encampa, por completo e sem nuances, a concepção de Trabalho Decente tal como adotada e fomentada pela cooperação internacional empreendida pela OIT. Desde então, outros três RDHs globais foram publicados pelo PNUD.

Sob o título "Desenvolvimento Humano para Todos", o RDH de 2016 volta a utilizar a expressão Trabalho Decente de modo incidental e pontual frente ao tema central do documento, não suscitando destaques que interessem a esta pesquisa (PNUD, 2016).

Já o RDH de 2018 - "Índices e Indicadores do Desenvolvimento Humano: Atualização Estatística de 2018" dedicou-se à apresentação de estatísticas atualizadas em forma de dezenas de tabelas, com dados mais específicos quando comparados às estatísticas dos RDHs anteriores, cujo conteúdo trouxe textos-base muito mais extensos e reflexivos. Embora não haja qualquer emprego do termo "Trabalho Decente", dentre as diversas tabelas apresentadas pelo RDH de 2018, há a Tabela 11 - "Trabalho e Emprego" (PNUD, 2018, p. 62-65), composta por 
indicadores por país relativos a quatro tópicos: emprego, desemprego, trabalho em condição de risco para o Desenvolvimento Humano e seguridade social relacionada ao emprego. Os indicadores sobre emprego retratam a taxa de emprego face ao quantitativo de população, a taxa de participação na força de trabalho, emprego na agricultura e emprego em serviços. Os indicadores sobre desemprego reportam números sobre desemprego total, desemprego juvenil e quantidade de jovens que não estão estudam ou trabalham. Os indicadores sobre trabalho em condição de risco para o desenvolvimento humano aludem a trabalho infantil e a trabalho em situação de pobreza (US\$ 3,10 pagos por dia). Finalmente, o indicador sobre seguridade social relacionada ao emprego revela a porcentagem da população elegível que recebe pensão por idade. No caso desta Tabela 11, o RDH 2018 adota, integralmente, o modelo estimativo da OIT para a composição de todos os indicadores utilizados.

O último dos RDHs lançados até o momento data do final do ano de 2019 e foi intitulado "Além da Renda, Além das Médias, Além do Hoje: Desigualdades no Desenvolvimento Humano no Século XXI". O documento, retomando a tradição das densas avaliações que precedem a apresentação da classificação de países quanto ao IDH e seus desdobramentos, dedica-se a propor um repensar das desigualdades atinentes ao Desenvolvimento Humano à luz da sociedade do século XXI e suas nuances em termos de forças econômicas, arranjos políticos e vicissitudes nacionais, partindo de uma avaliação sobre os avanços e retrocessos na luta pela redução das desigualdades para descortinar a necessidade de um novo olhar para as ações de diagnóstico e promoção do Desenvolvimento Humano, no que aparenta ser uma propostas de atualização das próprias bases estatísticas e promocionais do PNUD.

Segundo o RDH de 2019, o quadro examinado em retrospectiva e, então, posto em prospecção enseja o que o relatório denomina "cinco mensagens principais", a saber: as disparidades no desenvolvimento humano permanecem 
generalizadas, apesar de haver progressos na redução das privações extremas; está surgindo uma nova geração de desigualdades, com divergência nas capacidades avançadas, apesar da convergência nas capacidades básicas; as desigualdades acumulam-se ao longo da vida, refletindo, com frequência, desequilíbrios profundos de poder; a avaliação e a resposta às desigualdades no desenvolvimento humano exige uma revolução nas métricas (novos modelos estatísticos); é possível corrigir as desigualdades se houver ação imediata, antes que os desequilíbrios no poder econômico se consolidem politicamente (PNUD, 2019, p. 3).

O tema do trabalho permeia todas as reflexões apresentadas neste relatório, repisando a preocupação sob o ponto de vista das desigualdades de acesso à renda. Contudo, parte relevante do $\mathrm{RDH}$ de 2019 é dedicada ao trato de riscos e potencialidades das novas tecnologias para o ingresso, manutenção e exclusão das pessoas do mercado de trabalho, com foco em políticas de proteção de "empregos decentes" pela via dos salários mínimos em patamares dignos e de gestão apoiada para que trabalhadoras e trabalhadores possam estar aptos manterem-se no mercado de trabalho, em vista das novas exigências e postos laborais derivadas das mudanças tecnológicas, bem como para que tais pessoas estejam a salvo da informalidade que as distancia de direitos e da proteção social (PNUD, 2019, p. 199-219).

Neste contexto de análise, conquanto o RDH 2019 faça uso tópico das expressões "Trabalho Decente" ("Trabalho Digno" na tradução para o português) e "emprego decente", portanto não adotando a clara interação apresentada pelo RDH de 2015, aparentemente, não se pode afirmar ter havido descontinuidade da adoção da perspectiva do Trabalho Decente segundo a OIT, pois vê-se a adoção de estudos e modelos estatísticos da OIT ${ }^{16}$, inclusive quanto a métricas, dado que o RDH 2019 volta a lançar mão, dentro do painel de mensuração da "Qualidade do Desenvolvimento Humano", subgrupo "Qualidade do nível de vida”, de um indicador denominado "vulnerabilidade laboral", que diz respeito à informalidade, porquanto 
registra a percentagem de empregados contratados como trabalhadores familiares não remunerados e trabalhadores por conta própria, para tanto reproduzindo o modelo estatístico para o indicador da OIT.

\section{PERCEPÇÕES hOLÍSTICAS dO ITINERÁRIO DE CONVERGÊNCIA DO DESENVOLVIMENTO HUMANO COM O TRABALHO DECENTE}

Embora seja a OIT, desde os anos cinquenta, uma agência especializada da ONU e o PNUD um programa permanente criado, no mesmo período, pela mesma ONU, o exame documental envidado neste estudo mostra que o Trabalho Decente não foi uma concepção imediatamente acatada pelo PNUD. Se por um lado é certo que o termo "decent work" aparece em todos os RDHs examinados e que o trabalho compõe o rol de sete liberdades fundamentais ao Desenvolvimento Humano listadas já no RDH de 2000, por outro, é notório que a extensão das análises suscitadas envolvendo a expressão, por anos, permite inferir um inicial distanciamento da ideia esculpida pela OIT, marcadamente vinculada aos quatro objetivos estratégicos suscitados pelo Trabalho Decente.

Os documentos examinados revelam uma abordagem sempre presente das relações de trabalho, no mais das vezes, todavia, privilegiando o incentivo à geração de empregos remunerados e de qualidade como meio de combate ao principal motivo da pobreza e da miséria, qual seja, a privação de renda, circunstância essa, por sua vez, limitante das capabilities e, por conseguinte, do Desenvolvimento Humano ${ }^{15}$. É de se imaginar que este tipo de aproximação remonta à composição original do IDH (objeto dos RDHs), que não contempla o trabalho, mas apenas

\footnotetext{
${ }^{15}$ Em consonância com este cânone seniano e demonstrando que não se trata de desprezo pelo crescimento econômico, a importância do planejamento no fomento de empregos de qualidade e sua capacidade de gerar crescimento econômico sustentável é a tônica do trabalho longevo e disseminado de Ignacy Sachs (2004).
} 
renda, longevidade e educação. Tal Índice e sua composição, de seu lado, afiguramse manifestação prática de promoção da ideia de Sen sobre trabalho como fator de reforço das capacidades individuais, portanto, um meio para o Desenvolvimento Humano e não um elemento de sua conformação.

Entretanto, o distanciamento dos RDHs da concepção de Trabalho Decente segundo a OIT vai, gradativamente, sendo mitigado, movimento favorecido pela sucessiva abordagem de temas com alguma ligação com aquela concepção. É o caso do $\mathrm{RDH}$ de 2000 , que tem por mote a liberdade, explicitamente vinculada pela OIT ao primeiro dos objetivos estratégicos do Trabalho Decente (proteção de direitos humanos nas relações laborais). O mesmo se aplica ao RDH de 2001, o qual, ao tratar do avanço tecnológico e do seu impacto no mercado de trabalho, toca pelo menos dois objetivos estratégicos do Trabalho Decente: geração de empregos de qualidade e ampliação da proteção social. Assim também acontece com o RDH de 2002 e sua atenção dedicada à democracia, mencionando os sindicatos como agentes de participação social, assim alcançando a essência do diálogo social, quarto objetivo estratégico do Trabalho Decente.

Afigura-se plausível sustentar que tal mitigação evolui para um movimento direcionado à convergência com a ideia de Trabalho Decente, a partir do RDH de 2010, que, pensa-se, inaugura uma fase de uma atenção mais recorrente e conceitualmente mais densa dos $\mathrm{RDHs}$ quanto à matéria laboral. A maior recorrência e peremptoriedade de afirmações tais quais as que preceituam a dimensão subjetiva da atividade para além do auferimento de renda e a necessidade de proteção de direitos trabalhistas e da expansão da proteção social em face da sanha flexibilizadora neoliberal são exemplos vivos da contemplação mais sistematicamente conjugada das dimensões estratégicas do Trabalho Decente, pavimentando o caminho para a adoção formal desta concepção que seria verificada, de maneira inequívoca, no RDH de 2015. É igualmente de se vislumbrar a 
decisiva influência para tanto da literal contemplação do Trabalho Decente pelos ODS, preenchendo, assim, lacuna havida por ocasião dos seus antecessores ODM.

Porém, a clara conexão revelada pelo RDH de 2015 não voltou a verificarse nos relatórios posteriores. De todo modo, os RDHs de 2018 e 2019 parecem manter viva a aproximação institucional mais estável e homogênea quanto a conceitos e ações, bem como quanto a métricas atinentes ao Trabalho Decente, ainda que não o faça, explicitamente, tal qual verificado em 2015, pois ambos aqueles últimos relatórios permanecem valendo-se de usos tópicos do termo da OIT, embora seja possível perceber que a maioria dos objetivos estratégicos a esse vinculados sigam sendo contemplados pelas análises, em especial a geração de empregos de qualidade (com salários adequados e em condições de segurança pessoal), a proteção de direitos humanos no trabalho (sobretudo pelo combate à informalidade) e a ampliação da proteção social.

Por outro lado, conquanto o RDH de 2015 seja um marco para o reconhecimento formal, na seara da governança global, da associação entre Trabalho Decente e Desenvolvimento Humano, o mesmo não se pode afirmar sobre os mecanismos de monitoramento de dados. A esse respeito, é de se destacar que a tentativa de instituição de um indicador específico de medição do Trabalho Decente, em 2010 - bem-vindo, a despeito de suas deficiências metodológicas e de amplitude - não experimentou continuidade, não sendo retomada sequer por ocasião do RDH de 2015, mesmo contando a OIT, desde 2008, com diretrizes e debates avançados sobre a questão, o que permitiria um adensamento da convergência entre as atividades de pesquisa dos RDHs e da OIT, através, por exemplo, da mera adoção por aquele da proposta de indicadores dessa última.

Diante de todo pesquisado, é possível, finalmente, afirmar, em resposta ao problema de pesquisa posto que, tendo-se por referência os RDHs editados desde o ano 2000, é crível identificar um movimento gradativo de convergência entre PNUD e OIT no que se refere à promoção do Trabalho Decente e a seu conteúdo, 
movimento esse que alcança sua plenitude com o RDH 2015, ao adotar, de maneira inequívoca, a concepção de Trabalho Decente, o fazendo na qualidade de fator de reforço do Desenvolvimento Humano. Todavia, a consolidação e aprofundamento dessa aproximação, seja no nível teórico seja no das ações, ainda está por ser provada, notadamente considerando-se que os RDHs de 2016, 2018 e 2019 não evidenciam a sintonia explícita verificada em 2015, em que pese permitam entrever a manutenção dos laços construídos.

\section{CONCLUSÃO}

A pesquisa apresentada pretendeu enfrentar a indagação sobre se os RDHs, elaborados no marco do PNUD, adotam a concepção de Trabalho Decente. O fez tendo por procedimento a investigação do conteúdo dos RDHs globais, dedicados ao monitoramento do IDH, publicados desde o advento da concepção de Trabalho Decente como eixo nuclear da atuação da OIT.

Diante da extensa amostra documental examinada, foi possível perceber - a despeito do compartilhamento, no final do século XXI, da mesma matriz teórica econômico-filosófica inspiradora pelo PNUD e pela OIT - uma aproximação gradativa dos $\mathrm{RDH}$ em face dos objetivos estratégicos que derivam (e por isso denotam) a noção de Trabalho Decente, que evoluiu para uma abordagem cada vez mais alinhada, culminando com a adoção explícita dessa ideia em sua inteireza, no ano de 2015.

As consequências desse recente alinhamento para a governança global orientada à promoção do Desenvolvimento e do Trabalho Decente ainda estão por ser mensuradas e dependerão dos relatórios e movimentos vindouros do PNUD, mas é possível cogitar que tal associação, uma vez consagrada, poderá mostrar viabilidade para pautar, com autoridade e legitimidade advindas de sua natureza 
uníssona, a cooperação internacional com vistas ao compromisso dos Estados para com a proteção intransigente de direitos humanos trabalhistas e suas instituições garantes, a geração de empregos de qualidade, a ampliação da proteção (seguridade) social e o fomento do diálogo social em ambiente democrático, com vistas a fazer frente, portanto, aos cânones ultraliberais que tomaram de assalto as diretrizes macroeconômicas hegemônicas da atualidade.

\section{REFERÊNCIAS}

ALKIRE, Sabina; DENEULIN, Séverine. Introducing the human development and capability approach. An introduction to the human development and capability approach. London: Earthscan, 2009.

ALVES, J. A. Lindgren. A Cúpula Mundial sobre o Desenvolvimento Social e os paradoxos de Copenhague. Revista Brasileira de Política Internacional, v. 40, n. 1, p. 142-166, 1997.

AMARO, R. R. Desenvolvimento - Um conceito ultrapassado ou em renovação? Da teoria à prática e da prática à teoria. Cadernos de Estudos Africanos, n. 4, 2003, p. $40-60$.

A sustentabilidade das organizações de economia solidária: proposta de conceptualização e de avaliação. Revista de Economia Solidária, 1, 2006, p. 1129.

ANKER, Richard et al. La medición del trabajo decente con indicadores estadísticos. Revista Internacional del trabajo, v. 122, n. 2, p. 161-195, 2003.

CALEGARE, Marcelo Gustavo Aguilar; SILVA JÚNIOR, Nelson da. Progresso, desenvolvimento sustentável e abordagens diversas de desenvolvimento: uma sucinta revisão de literatura. Desenvolvimento e Meio ambiente, v. 24, p. 39-56, 2011.

FURTADO, Celso. Formação de Capital e Desenvolvimento Econômico. Revista Brasileira de Economia, Rio de Janeiro, v. 06, n. 03, p.07-47, dez. 1951. 
. Os Desafios da Nova Geração. Revista de Economia Política, São Paulo, v. 24, n. 4, p.483-486, out./dez. 2004.

GARRIDO, Pablo Sanchez. Raíces intelectuales de Amartya Sen: Aristóteles, Adam Smith y Karl Marx. Madrid: Centro de Estudos Políticos y Constitucionales, 2008.

HUNT, L. A Nova história cultural. 3. ed. São Paulo: Martins Editora, 2001.

ILO - INTERNATIONAL LABOUR ORGANIZATION. Tripartite Meeting of Experts on the Measurement of Decent Work: Chairperson's report. Geneva: ILO, 2008. Disponível em: <https://www.ilo.org/wcmsp5/groups/public/---dgreports/--integration/documents/meetingdocument/wcms_099764.pdf>. Acesso em: 19 jul. 2019.

OIT. CONFERENCIA INTERNACIONAL DEL TRABAJO. Memoria del Director General: trabajo decente (1999). Ginebra: OIT, 1999. Disponível em: <http://www.ilo.org/public/spanish/standards/relm/ilc/ilc87/rep-i.htm> . Acesso em 08 ago. 2019.

PNUD. Informe sobre Desarrollo Humano 2016. Desarrollo humano para todas las personas. Nueva York: PNUD, 2017.

. Relatório do Desenvolvimento Humano 2015. O Trabalho como Motor do Desenvolvimento Humano. Nova lorque: PNUD, 2015.

. Relatório do Desenvolvimento Humano 2014. Sustentar o Progresso Humano: Reduzir as Vulnerabilidades e Reforçar a Resilência. Nova lorque: PNUD, 2014.

. Relatório do Desenvolvimento Humano 2013. A Ascensão do Sul: Progresso Humano num Mundo Diversificado. Nova lorque: PNUD, 2013.

. Relatório do Desenvolvimento Humano 2011. Sustentabilidade e equidade: Um futuro melhor para todos. Nova lorque: PNUD, 2012.

Relatório do Desenvolvimento Humano 2010. A Verdadeira Riqueza das Nações: Vias para o Desenvolvimento Humano. Nova lorque: PNUD, 2010.

. Relatório do Desenvolvimento Humano 2009. Ultrapassar Barreiras: Mobilidade e desenvolvimento humanos. Nova lorque: PNUD, 2009. 
Relatório do Desenvolvimento Humano 2007/2008. Combater a mudança o clima: Solidariedade Humana em um mundo dividido. Nova lorque: PNUD, 2007.

. Relatório do Desenvolvimento Humano 2006. Além da escassez: poder, pobreza e a crise mundial da água (Resumo). Nova lorque: PNUD, 2006.

. Relatório do Desenvolvimento Humano 2005. Cooperação Internacional Numa Encruzilhada. Nova lorque: PNUD, 2005.

Relatório do Desenvolvimento Humano 2004. Liberdade Cultural num Mundo Diversificado. Nova lorque: PNUD, 2004.

PNUD. Relatório do Desenvolvimento Humano 2003. Um pacto entre nações para eliminar a pobreza humana. Nova lorque: PNUD, 2003.

. Relatório do Desenvolvimento Humano 2002. Aprofundar a democracia num mundo fragmentado. Nova lorque: PNUD, 2002.

- Relatório do Desenvolvimento Humano 2001. Fazendo as novas tecnologias trabalhar para o desenvolvimento humano. Nova lorque: PNUD, 2001.

SACHS, I. Inclusão social pelo trabalho decente: oportunidades, obstáculos, políticas públicas. Estudos Avançados, v. 18, n. 51, p. 23-49, 2004.

SANTOS, Boaventura de Sousa. A crítica da razão indolente: contra o desperdício da experiência. 2. ed. Porto: Edições Afrontamento, 2002.

SCHWAB, Klaus. A Quarta Revolução Industrial. Trad. Daniel Moreira Miranda. São Paulo: Edipro, 2016.

SEHNBRUCH, Kirsten et al. Human development and decent work: why some concepts succeed and others fail to make an impact. Development and Change, v. 46, n. 2, $\quad$ p. 197-224, 2015. Disponível em: <https://onlinelibrary.wiley.com/doi/abs/10.1111/dech.12149>. Acesso em: 02 ago. 2019.

SEN, Amartya. Sobre ética e economia. Trad. Laura Teixeira Motta. São Paulo: Companhia das Letras, 1999.

Desenvolvimento como liberdade. Trad. Laura Teixeira Mota. São Paulo: Companhia das Letras, 2010. 
. Work and rights. International Labour Review, Genebra, v. 139 (2), p. 119-128, 2000.

SO, Alvin Y. Social Change and Development: Modernization, Dependency, and World-System Theories. Londres: Sage, 1990.

UNDP. Human Development Report 2006. Beyond scarcity: power, poverty and the global water crisis. New York, NY: UNDP, 2006.

- Human Development Report 2000. Human Rights and Human Development. New York: UNDP, 2000. 